\title{
The Role of MDCT Angiography in Preoperative Evaluation of the Living Renal Donors
}

\author{
AHMED M. ALAA ELDIN, M.D. and HEBA F. TANTAWY, M.D. \\ The Department of Radiodiagnosis, Faculty of Medicine, Zagazig University, Egypt
}

\begin{abstract}
Background: Renal transplantation is the treatment of choice for patients with end stage renal disease. The transplant surgeon needs accurate preoperative data about the anatomy of renal vasculature to reduce the hazards associated with the procedure. MDCTA is used because it is less invasive, simply appropriate and accessible. It allows accurate imaging of the normal and variant anatomy of the renal vasculature.
\end{abstract}

Aim of Study: To investigate the role of multidetector computed tomography angiography (MDCTA) in evaluating the preoperative anatomy of the renal vasculature in potential renal donors.

Subjects and Methods: A total of 30 patients underwent MDCTA as a routine work-up for live renal donors. The number of branches of renal arteries and veins, together with the frequency of incidental findings of the renal parenchyma were assessed. Multiplanar reformations, maximum intensity projections, and volume renderings were used. The results gained were surgically correlated.

Results: We recognized surgically important vascular variants and renal parenchymal abnormalities. Eight of 30 (27\%) subjects were excluded based on the MDCTA findings, due to vascular causes in 4 cases, recipient death in 2 cases, renal stones in one case, and a horse-shoe kidney in one case. The surgical decision of right nephrectomy was made in one case $(4.5 \%)$ due to complex vascular anatomy on the left side identified on MDCTA. The surgically established sensitivities of MDCTA data for the detection of the renal arteries and veins were $100 \%$ and $95.5 \%$, respectively.

Conclusion: MDCTA correctly detected essential exclusions for renal donation and aided the choice of the preferred kidney to be harvested based on parenchymal and va scular findings.

Key Words: Multidetector computed tomography angiography - Renal transplant donors - Renal transplantation.

\section{Introduction}

THE evaluation of potential renal transplant donors has become an essential task of radiologists, as

Correspondence to: Dr. Ahmed M. Alaa Eldin,

E-Mail: samadahmed78@yahoo.com renal transplantation from living related donors is the best treatment for patients with end stage renal disease. Previous studies have attempted to evaluate the role of multidetector computed tomography angiography (MDCTA) [1]

MDCTA is considered a promising technique because it enables the radiologist to provide the transplant surgeon with accurate preoperative data about the anatomy of the renal vasculature, to reduce the hazards associated with the procedure and to increase the likelihood of a successful outcome [2]

Although conventional angiography is still considered the gold standard in renal vascular imaging, but it is an invasive technique and exposes patients to high dose of ionizing radiation [3] .

So we aimed in this study to assess the role of MDCTA in the evaluation of the preoperative anatomy of the renal vasculature of potential renal donors as it is considered appropriate, less invasive and accessible.

\section{Patients and Methods}

Ethical statement:

Our institutional review board approved the study, and informed consent was obtained from each patient before their inclusion in the study. We followed the ethical principles of the Declaration of Helsinki during the preparation of this study.

\section{Study population:}

This prospective study was conducted in the period from January 2017 to August 2018 at Zagazig University Hospital and Al-Ahrar Hospital. The study included 30 consecutive adult patients (18 males and 12 females; age range 22-45 years; mean age $35.64 \pm 7.51$ years). All patients underwent 
MDCTA after being assessed by clinical examination, a laboratory renal function test, sonography and intravenous urography by the renal transplantation team work to evaluate them as potential living donors for renal transplantation. Twentyfive $(83 \%)$ of the potential donors were related to the recipients, while five $(17 \%)$ were unrelated to the recipients.

\section{MDCT protocol:}

A 128 detectors scanner (Philips Healthcare Ingenuity 128 raw MDCT) available in both institutions was used in all cases. The scan parameters were as follows: A section thickness of $2.5 \mathrm{~mm}$, a beam pitch of 1.5 , a detector array of $4 \times 2.5 \mathrm{~mm}$, a table speed of $15 \mathrm{~mm} / \mathrm{s}$ and a reconstruction increment of $2 \mathrm{~mm}$. The patient fasted for 5 hours prior to the procedure. The patient was in a supine position in the head-first technique with their arms above their head. Pre-contrast series from the 11 th thoracic vertebra to the symphysis pubis were obtained to:

- Identify the site of the renal hilum and the kidney level.

- Detect urolithiasis and any calcification.

- Provide a non-enhancing baseline for any indeterminate renal mass lesion.

A $18 \mathrm{~g}$. cannula was inserted into the anti-cubital fossa, and 100 to $120 \mathrm{cc}$ of non-ionic iodinated contrast agent (Iopromide, Ultravist) was injected via a mechanical injector at an injection rate of 3.5 to $4 \mathrm{ml} / \mathrm{sec}$.

\section{Three contrast phases were obtained:}

1- Arterial phase: Scanning began just after a triggering threshold of $80 \mathrm{HU}$ in the region of interest located in the abdominal aorta at the level of renal hilum. The main acquisition parameters for the arterial phase were: A tube voltage of $120 \mathrm{kv}$, a tube current of $200 \mathrm{mAs}$, and a gantry speed of $0.5 \mathrm{~s} /$ rotation.

2- Nephrographic phase: Scanning began $40 \mathrm{sec}-$ onds after the end of the arterial phase. Both phases were taken from the 11th thoracic vertebra to the common iliac artery bifurcation.

3- Excretory phase: Scanning began approximately 300 seconds after the end of the nephrographic phase from the 11th thoracic vertebra to the lower end of the symphysis pubis.

Image processing and analysis:

Directly after acquisition of the CT images, data was transferred to workstation. The conveyed data included pre-contrast, arterial, nephrographic and excretory phase images. Arterial phase CT images were evaluated with respect to whether the renal vessels were sufficiently enhanced; sufficient enhancement was considered when both renal arteries and veins were well opacified through their entire length and the renal arteries were simply distinguished from the renal veins, as the arteries enhanced more than the veins did. Axial images of the arterial phase were carefully viewed for accessory arteries, venous variation, and any arterial pathological lesion. Next, the maximum intensity projection (MIP) in the coronal oblique and axial oblique planes was applied to demonstrate the abdominal aorta, the full length of both renal arteries from their origin down to the level of the segmental branches and also to demonstrate the veins. These MIP images can be reconstructed after the subtraction of bony structures and other irrelevant soft tissues, thus constructing images that mimic those of conventional angiography. Furthermore, the volume rendering (VR) technique was used to create three-dimensional (3D) images to showthe abdominal aorta, renal arteries, and renal veins. Both MIP and VR images were photographed at fifteen degrees $\left(15^{\circ}\right)$ of rotation along the $\mathrm{z}$-axis of the body at window and level settings for optimal vascular demonstration. On the 3D images, the following points were assessed:

- The number of renal arteries.

- The presence of early arterial branching, which was defined as present when any branch arose within $1.5 \mathrm{~cm}$ from the aorta.

- Arterial abnormalities such as stenosis and aneurismal dilatation.

- The number of veins.

- Late venous confluence, which was defined as present when veins united within $1 \mathrm{~cm}$ from the inferior vena cava.

- Venous abnormalities such as a retro-aortic or circum-aortic veins.

CT nephrographic axial images were carefully viewed for any mass lesion or parenchymal defect. MIP and VR images were thenconstructed to make acomprehensive evaluation of the renal parenchyma. CT urographic images were produced from the excretory phase CT data by utilizing VR and MIP in the oblique coronal plane. The slab thickness was determined to involve both pelvi-calyces and ureters. The CT urographic images were examined to determine whether the whole urinary tract was satisfactorily opacified and whether there were structural abnormalities in the urinary tract involving pelvi-ureteric masses or strictures. 


\section{Reference standard:}

The degree of agreement of our findings was obtained from intraoperative correlation after obtaining properly documented surgical reports for all cases that contained information about the selected side of donation, the number of renal vessels and any additional surgical procedures. Surgical findings, including the number of arteries and veins, early branching arteries, and venous anomalies in each kidney, were recorded, as well as any abnormality in the renal parenchyma.

\section{Statistical analysis:}

Data are presented as the mean \pm SD and were processed and analysedusing (SPSS version 20). The diagnostic performance of MDCTA compared to surgical findings was calculated. The interobserver agreement between MDCT and surgical findings was estimated by using Cohen's kappa $(\kappa)$ test and $95 \%$ confidence intervals (CIs). The $\kappa$ values were interpreted as follows: Poor agreement $=0.01-0.20$; fair agreement $=0.21-0.40$; moderate agreement $=0.41-0.60$; good agreement $=0.61-0.80 ;$ and excellent agreement $=0.81-1.0$. A $p$-value $\leq 0.05$ was regarded as statistically significant.

\section{Results}

\section{Study population:}

A total of 30 potential renal donors were included in the study. The findings were divided into nonvascular and vascular. The vascular findings were subdivided into arterial findings (renal artery accessories, pre-hilar arterial branching, renal artery aneurysm, renal artery stenosis and fibromuscular dysplasia) and venous findings (retroaortic left renal vein and circum-aortic left renal vein). All were diagnosed on MDCTA by analysis of the axial images, 3D MIP and VR (Table 1).

A total of 22 donors (age range, 22-45 years; mean age, $35.5 \pm 7.4$ years), comprising 17 males (age range, $22-43$ years; mean age, $34.2 \pm 8.4$ years) and 5 females (age range, 25-45 years; mean age, $37.66 \pm 10.4$ years), were enrolled in a renal transplantation programme and proceeded to nephrectomy after having MDCTA and being deemed appropriate for inclusion in the study based on the MDCTA findings. Eight subjects (27\%) were excluded due to presence of horseshoe fused kidneys, left circum-aortic renal vein \& right renal artery fibromuscular dysplasia. (Figs. 1-3) (Table 2).

\section{MDCTA findings:}

We found a single renal artery in 16/22 (73\%) of the examined donors, with one $(4.5 \%)$ having a single artery and a retro-aortic left renal vein and another $(4.5 \%)$ with pre-hilar branching of the renal artery on both sides (Fig. 4). We detected multiple renal arteries in 4/22 (18\%) donors, bilateral double arteries $(n=1)$ (Fig. 5), left double arteries $(n=1)$, and right double arteries $(n=2)$ (Table 2).

We depicted a single renal vein on both sides in $100 \%(22 / 22)$ of donors, while no multiple veins were detected. We founda left retro-aortic vein in one donor (4.5\%), and an ante-aortic left renal vein in 21donors $(95.5 \%)$ (Table 2$).$

\section{Surgical findings:}

The total number of donors selected for nephrectomy was $22(73 \%)$ of the 30 donors in the study. The left kidney was donated in 21/22 (95.5\%) donors; a single renal artery was found in 20 (91\%) among the left kidneys donated (as there were two cases of right accessory renal arteries, while their left side artery was single) and an accessory renal artery was found in one donor. The right kidney was taken in $1 / 22(4.5 \%)$ donor due to a supernumerary artery on the left side containing a single artery (Table 2).

We found a single renal vein in $21 / 22(95.5 \%)$ donors, and double renal veins in one (4.5\%) donor during surgery. We found left retro-aortic vein in one $(4.5 \%)$ donor, and ante-aortic left veins in the remaining 22 (95.5\%) donors (Table 2).

Table (1): Initial MDCTA of vascular and non-vascular findings of 30 potential donors.

\begin{tabular}{llc}
\hline & $\mathrm{N}(\%)$ & Lateralization \\
\hline Vascular & & \\
Arterial: & & \\
- Normal single artery & $18(60)$ & Bilateral \\
- Pre-hilar branching & $1(3)$ & Bilateral \\
- Accessory arteries & $4(13)$ & 2 right, 1 bilateral and 1 left \\
- Artery aneurysm & $1(3)$ & Right \\
- Artery stenosis & $1(3)$ & Bilateral \\
- Arterial fibromuscular & $1(3)$ & Right \\
$\quad$ dysplasia & & \\
Venous: & & Left \\
- Circum-aortic renal vein & $1(3)$ & Left \\
- Retro-aortic renal vein & $1(3)$ & \\
Nonvascular: & & Bilateral \\
- Stones & $1(3)$ & \\
- Horse-shoe kidney & $1(3)$ & \\
\hline
\end{tabular}


Table (2): Exclusion and inclusion criteria of our potential donors for transplantation.

\begin{tabular}{|c|c|c|}
\hline & Criteria & No $(\%)$ \\
\hline \multirow[t]{3}{*}{$\begin{array}{l}\text { Exclusion Criteria } \\
\mathrm{N}=8(27 \%)\end{array}$} & $\begin{array}{l}\text {-Recipient death } \\
\text {-Donor health problems } \\
\text { diagnosed by MDCTA: }\end{array}$ & $2(25 \%)$ \\
\hline & $\begin{array}{l}\text { - Nonvascular: } \\
\text { a-Bilateral renal stones } \\
\text { b-Horse-shoe kidney }\end{array}$ & $\begin{array}{l}1(12.5) \\
1(12.5)\end{array}$ \\
\hline & $\begin{array}{l}\text { - Vascular: } \\
\text { a-Renal artery aneurysm } \\
\text { b-Renal artery stenosis } \\
\text { c-Fibromuscular dysplasia } \\
\text { d-Circum-aortic left } \\
\text { renal vein }\end{array}$ & $\begin{array}{l}1(12.5) \\
1(12.5) \\
1(12.5) \\
1(12.5)\end{array}$ \\
\hline \multirow[t]{4}{*}{$\begin{array}{l}\text { Inclusion Criteria } \\
\mathrm{N}=22(73 \%)\end{array}$} & $\begin{array}{l}\text {-Normal (single renal artery } \\
\text { on each side with normal } \\
\text { hilar branching and } \\
\text { normal renal veins). }\end{array}$ & $16(73)$ \\
\hline & $\begin{array}{l}\text {-Normal single renal artery } \\
\text { on each side with retro- } \\
\text { aortic left renal vein }\end{array}$ & $1(4.5)$ \\
\hline & $\begin{array}{l}\text {-Single artery with pre-hilar } \\
\text { arterial branching }\end{array}$ & 1 (4.5) bilateral \\
\hline & -Renal artery accessories & $\begin{array}{l}4(18) \\
\text { Right=2 (50) } \\
\text { Left=1 (25) } \\
\text { Bilateral=1 (25) }\end{array}$ \\
\hline
\end{tabular}

MDCTA=Multidetector computed tomography angiography.

\section{Agreement between MDCTA and surgical findings:}

As regard arterial findings, there was complete agreement between the results obtained by MDCTA and those observed at nephrectomy. In the 21 donors that donated their left kidney, a single artery was surgically found in all of them that were previously reported in MDCTA findings. Additionally, in the one donor who donated his right kidney, a single artery was surgically found and was previously reported in MDCTA (Table 3).

Table (3): Number and variations of renal arteries and veins depicted by MDCTA and those found at nephrectomy.

\begin{tabular}{cccccc}
\hline & & & & MDCTA & $\begin{array}{c}\text { Neph- } \\
\text { rectomy }\end{array}$ \\
\hline Arteries Left kidney & 21 & Single artery & 20 & 20 \\
& & & $\begin{array}{l}\text { Double arteries } \\
\text { Single artery }\end{array}$ & 1 & 1 \\
Veins & \multirow{2}{*}{ Right kidney } & 1 & Double arteries & 0 & 1 \\
& Left kidney & 21 & Single vein & 20 & 19 \\
& & & Retro-aortic & 1 & 1 \\
& & & Double veins & 0 & 1 \\
& Right kidney & 1 & Single vein & 1 & 1 \\
& & & Double veins & 0 & 0 \\
\hline
\end{tabular}

MDCTA=Multidetector computed tomography angiography.
With regard to the venous findings, there was a difference in the results of the renal veins described by MDCTA and nephrectomy findings. In one donor, a vein was reported as single by MDCTA but surgically, double veins were detected (Table 4).

Table (4): Comparison of MDCTA with surgical findings.

\begin{tabular}{lcc}
\hline Findings & MDCTA & Surgery \\
\hline Single artery & 16 & 16 \\
Accessory arteries & 4 & 4 \\
Pre-hilar branching & 1 & 1 \\
Retro-aortic renal vein & 1 & 1 \\
Accessory renal vein & 0 & 1 \\
\hline
\end{tabular}

MDCTA=Multidetector computed tomography angiography.

The MDCTA anatomy matched with the surgical findings for the 22 donors, for $100 \%$ of arteries and $95.5 \%$ for veins, resulting in a sensitivity of $100 \%$, and $95.5 \%$ for arteries and veins, respectively, and a specificity of $100 \%$ for both the arteries and veins. The accuracy rate was $100 \%$ for arteries and $95.5 \%$ for veins, with no false-positive MDCTA interpretations and only one case of false-negative interpretation in comparison with the surgical findings of the 22 donors who underwent nephrectomy (Table 5). Therefore, there was no significant difference between the MDCTA and surgical findings $(p=1.000)$. Furthermore, there was good agreement between the MDCTA and surgical findings $(\mathrm{k}=0.800)$.

Table (5): The diagnostic performance and inter-observer agreement of MDCTA in the detection of renal arteries and veins in comparison to surgical findings as the reference standard.

\begin{tabular}{|c|c|c|c|c|c|c|}
\hline & \multirow{2}{*}{ Arteries } & \multirow{2}{*}{ Veins } & \multirow[b]{2}{*}{$\mathrm{k}$} & \multicolumn{2}{|c|}{$\begin{array}{c}\text { Inter-observer } \\
\text { Agreement }\end{array}$} & \multirow{2}{*}{$\begin{array}{c}p- \\
\text { value }\end{array}$} \\
\hline & & & & $\begin{array}{l}\text { Standard } \\
\text { Error }\end{array}$ & $\begin{array}{l}95 \% \\
\text { CI }\end{array}$ & \\
\hline Sensitivity & $100 \%$ & $95.5 \%$ & 0.800 & 0.169 & $0.468-1.000$ & 1.000 \\
\hline Specificity & $100 \%$ & $100 \%$ & & & & \\
\hline PPV & $100 \%$ & $100 \%$ & & & & \\
\hline NPV & $100 \%$ & $0.00 \%$ & & & & \\
\hline Accuracy & $100 \%$ & $95.5 \%$ & & & & \\
\hline
\end{tabular}

$\mathrm{k}=\mathrm{Kappa}$

$\mathrm{CI}=$ Confidence interval 

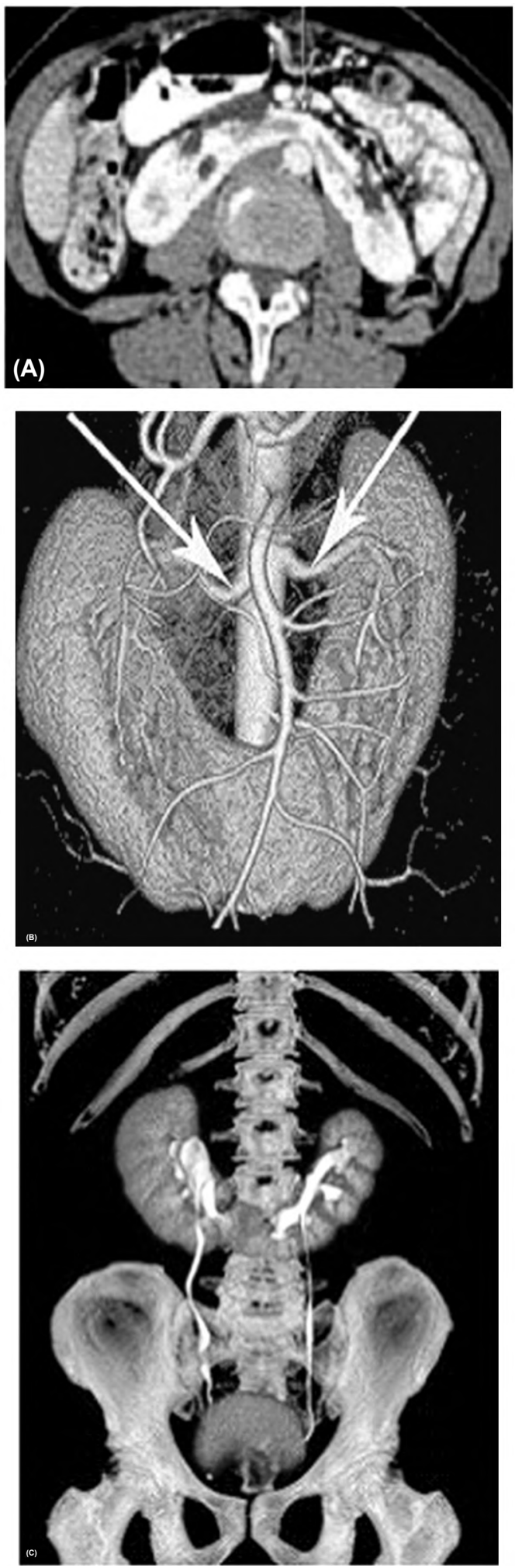

Fig. (1-A): 40-year-old female renal donor. (A) MDCTA axial image shows fused kidneys at their lower poles and the isthmus is seen anterior to the aorta. (B) MDCTA VR image shows kidneys fused at their lower poles, with the isthmus seen anterior to the aorta (red arrow) and single renal arteries of both fused kidneys (white arrows). (C) MDCT urography 3D image shows fused kidneys and two single ureters (orange arrows) with the isthmus seen anterior to the vertebral column. This case was surgically excluded.
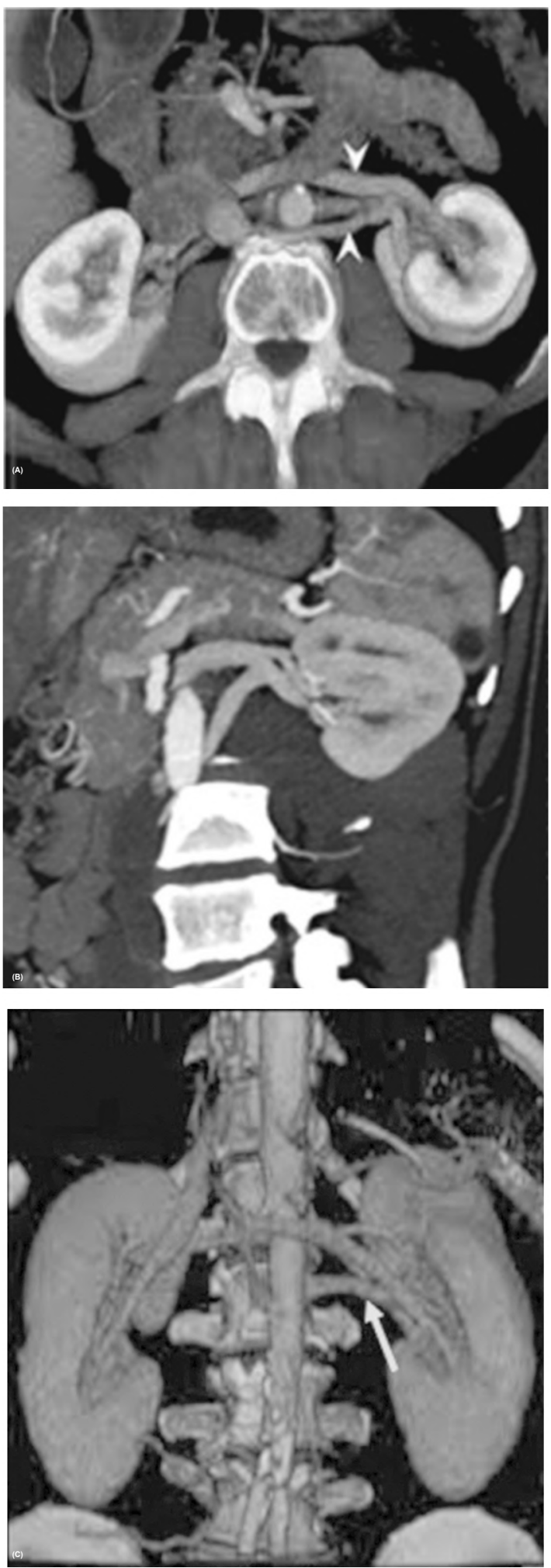

Fig. (2-A): 33-year-old male renal donor. (A) MDCTA axial image in the venous phase shows the left renal vein dividing into two tributaries that are circling the aorta before entering the inferior vena cava on the right side of the aorta (arrow heads). (B) and (C) MDCTA sagittal and VR images in the late arterial phase where the left circum-aortic renal vein was also found (orang arrow). This case was surgically excluded. 

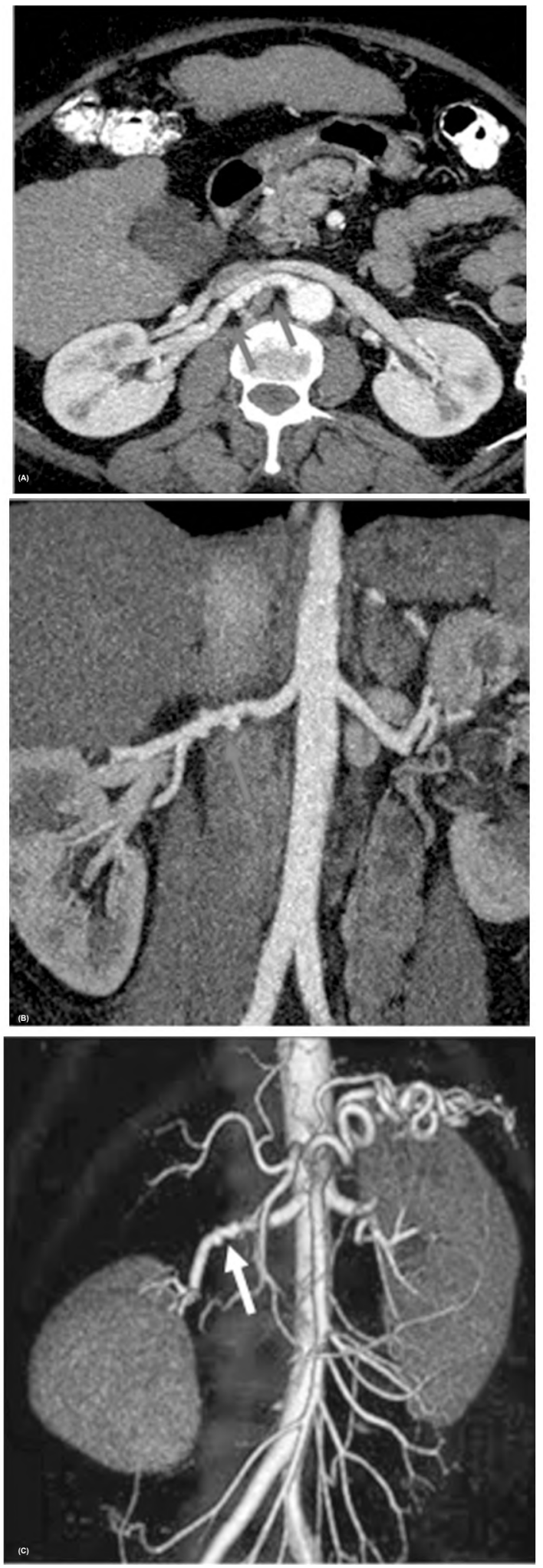

Fig. (3-A): 42-year-old female renal donor. (A) and (B) MDCTA axial and coronal images in the arterial phase show the beaded appearance of the right renal artery matching with fibromuscular dysplasia (red arrows). (C) MDCTA VR image in the arterial phase demonstrates the beaded appearance of the right renal artery denoting fibromuscular dysplasia (white arrows). This case was surgically excluded.
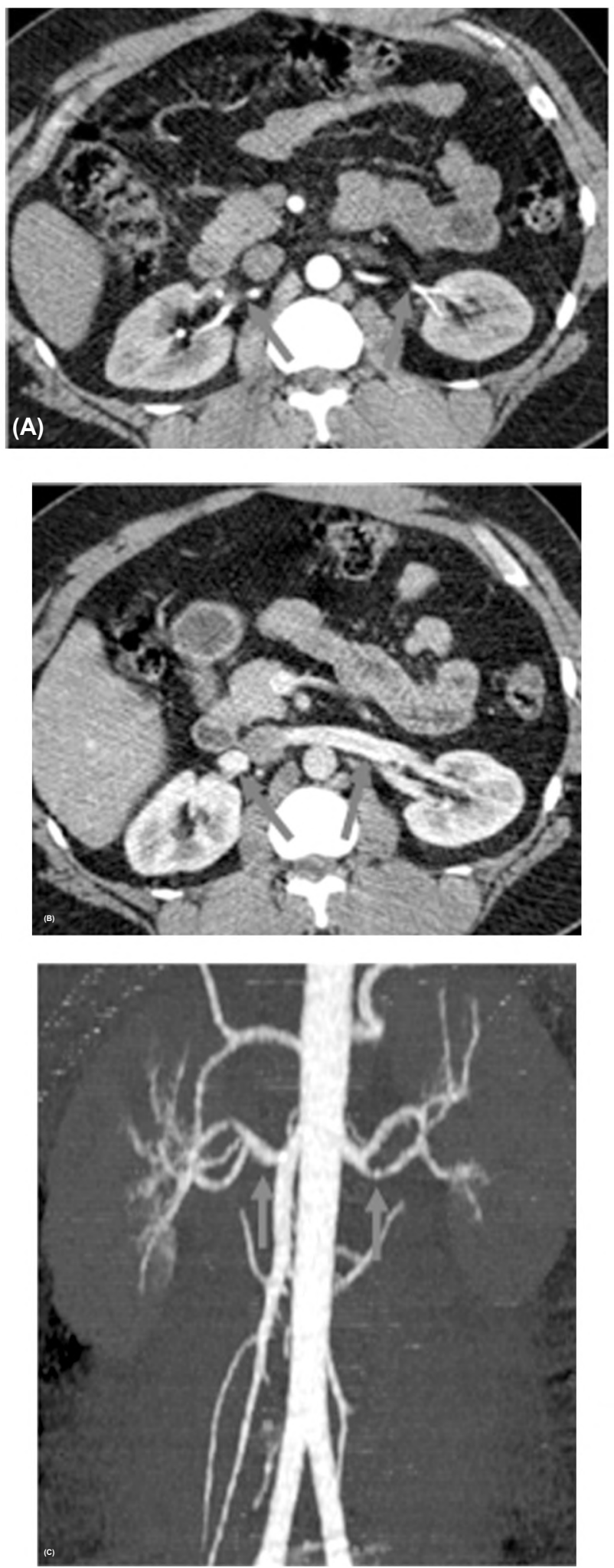

Fig. (4-A): 43-year-old male renal donor. (A) and (B) MDCTA axial images in the arterial phase show single right and left renal arteries with pre-hilar branches and the site of branching (red arrows) seen $2.5 \mathrm{~cm}$ from the aortic origin.(C) MDCTA MIP image in the arterial phase shows single right and left renal arteries and pre-hilar branching (red arrows). This case underwent surgery, and the left kidney was donated. The operative findings were a single left renal artery with pre-hilar branching and a single vein. 

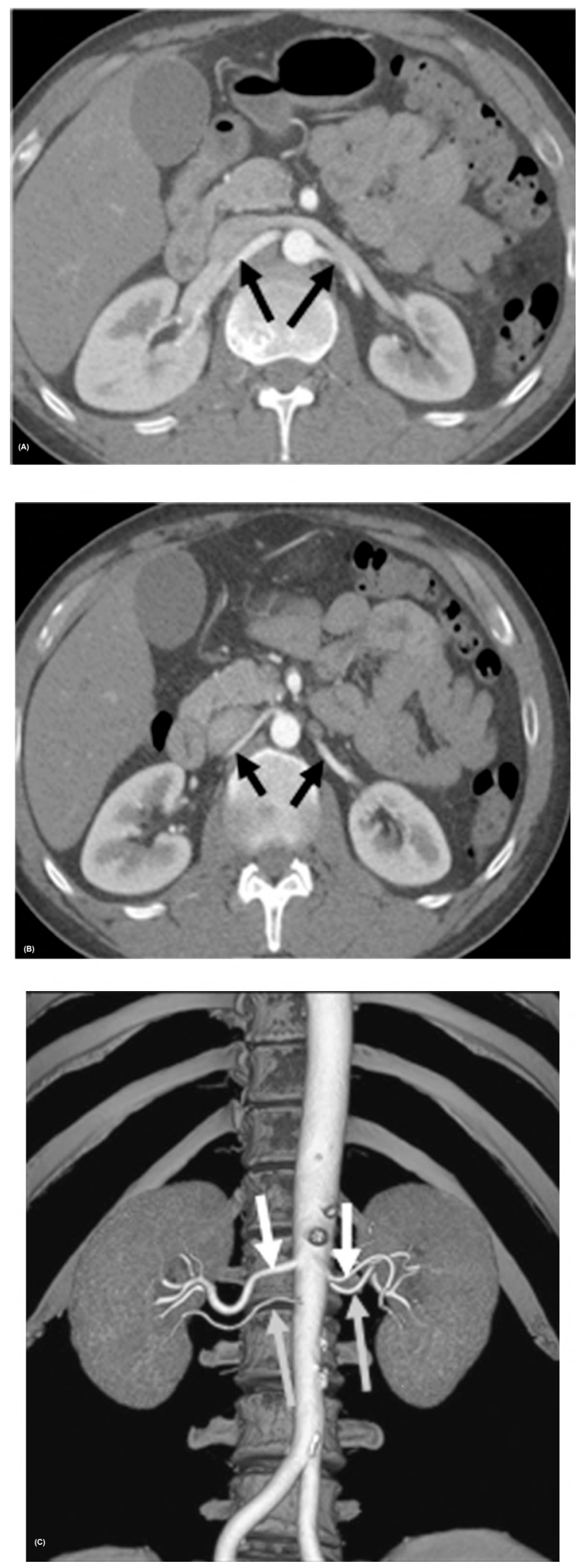

Fig. (5-A): 43-year-old female renal donor. (A) MDCTA axial image in the early arterial phase shows main right and left renal arteries (black arrows). (B) MDCTA axial image in the arterial phase in lower CT axial cut shows right and left renal accessory arteries (black arrows). (C) MDCTA 3D image shows the main right and left renal arteries (white arrows) and bilateral renal accessory arteries (orange arrows). This case underwent surgery, and the left kidney was donated. The operative findings were double left renal arteries and a single vein.

\section{Discussion}

Renal transplantation is the management of choice for patients with end stage renal disease. Developments in imaging have provided a rapid and relatively non-invasive assessment of a donor's renal anatomy. Multiplanar reformation and 3D images obtained by CT provide a wide range of data [4].

The current study aimed to evaluate the role of MDCTA in the assessment of the preoperative anatomy of the renal vasculature and its variation in potential renal donors. A total of 30 potential renal donors were enlisted in the present study (18 males and 12 females), ranging in age from 22 to 45 years. Twenty-five $(83 \%)$ of them were related to the recipients and five (17\%) were not related. All potential donors underwent to MDCTA as a preoperative evaluation. They were referred for MDCTA after being assessed by clinical examination, a laboratory renal function test, sonography and intravenous urography by the renal transplantation team. Scanning prior to contrast administration to exclude nephrolithiasis was performed.

In the present study, the Philips Healthcare Ingenuity 128 raw MDCT scanner was used with a collimation of $0.5 \mathrm{~mm}, 120 \mathrm{kVp}$, a slice thickness of $0.75 \mathrm{~mm}$, a rotation speed of 33 gantry, a nominal beam pitch of 1.5 , a table speed of $15 \mathrm{~mm}$ per rotation and a reconstruction increment of $2 \mathrm{~mm}$ (detector array of $4 \times 2.5 \mathrm{~mm}$ ), which is different from previous studies, such as the Alam [8] study, in which single-detector row helical CT scanners with a section thickness of $3 \mathrm{~mm}$, a pitch of 1.33 2 , and a table speed of $4 \mathrm{~mm} / \mathrm{sec}$ were used. Scanning parameters differences indicate that MDCT can give more compact volume data and provide faster scanning than a single-detector helical CT scanner. Also, the 3 Dimage quality is better with the use of MDCT.

Potential complications of the Ding et al., [6] study included extravasation of contrast material, a contrast hypersensitivity reaction and an increase in creatinine level. However, in our study, none of the 22 donors experienced extravasation of contrast material or any hypersensitivity reaction.

Asghari et al., [5] reported that multiple renal arteries are the most common finding in potential renal donors and have been described in 24-27\% of renal arteriograms. The detection of early prehilar branching is significant, as it may represent a contraindication to surgery, as adequate arterial 
length must be present to offer a sufficient arterial trunk for vascular anastomosis and to allow for surgical clamping. This variation was seen in $6 \%$ of renal donors [7].

Our study reported that multiple renal arteries were detected in four (18\%) cases of the 22 renal donors and an early branching renal artery was found in one $(4.5 \%)$ subject who had bilateral prehilar branching, which was not considered as an exclusion from surgery, therefore, he underwent a successful donation surgery. This consideration was not consistent with Asghari et al., [5] who reported that early branching renal arteries have been considered technically in the same manner as a double renal artery from a surgical point of view, as it requires a longer ischemic time; therefore, they excluded that variant from surgery.

In our study, there were several detected venous variants such as a circum-aortic left renal vein, which was seen in one case thatwas excluded from surgery; and the other venous variant was a retroaortic left renal vein that was detected. We also observed one case of bilateral single renal arteries that underwent donation. According to the Alam [8] study, the preoperative detection of a circumaortic left renal vein helps to prevent laceration of the vein during graft procurement and does not represent a contraindication to transplantation, but it helps to avoid the increased blood loss, a prolonged operating time and morbidity; however, in that study, they found only one case with a retroaortic left renal vein, representing $3.33 \%$ of included subjects.

No accessory veins were detected by MDCTA in our study. However, in the Alam [8] study; four accessory veins were identified on MDCTA (two on the right and two on the left).

For the non-vascular findings, in our study, bilateral renal calculi were detected in one case, representing $3 \%$ of all renal donors; this patient was excluded from surgery. A horse-shoe kidney anomaly was detected in one case; this patient was also excluded from surgery. However according to the Alam [8] study, one case had a calculus in the right upper pole calyx that was not discovered and the patient submitted to a successful lithotripsy of the renal calculus before surgery and three other cases had simple cortical cysts.

The performance of MDCTA in this study was superior in the preoperative evaluation of the renal vessels. Our MDCTA findings agreed with the surgical findings regarding the number of arteries in $100 \%$ of donated kidneys, in comparison with previous studies which reported values of $90 \%$ 95\% [9]. Moreover, in our study, The sensitivity and specificity for identifying supernumerary arteries were $100 \%$ and $100 \%$, respectively. These were higher than that reported in previous study (77\% and $89 \%$, respectively). We believe that 3D volume rendering and automatic bolus tracking contributed to these better results [10]

In this study, comparison of the MDCTA and preoperative findings revealed that the MDCTA anatomy of the renal vasculature matched the surgical findings for the 22 donors for $100 \%$ of arteries and $95.5 \%$ of veins, as one very small accessory vein was missed on MDCTA and detected during surgery. The sensitivity was $100 \%$ and $95.5 \%$ for arteries and veins, respectively, and the specificity was $100 \%$ for both arteries and veins. The accuracy rate was 100\% for arteries and $95.5 \%$ for veins; these results were superior to the those reported by Monton et al., [9] who reported that the accuracy of MDCTA in detecting renal venous anatomy, accessory arteries and pre-hilar branching, were in the range of $90-99 \%, 78-98 \%$ and $89-99 \%$ respectively. The results of the Asghari et al., [5] study were somewhat different from our results, as they reported that the sensitivity, specificity, and accuracy of detecting the number of main renal arteries was $96.8 \%$ and of veins were $100 \%$, while the sensitivity, specificity, and accuracy of detecting accessory arteries was $50 \%, 100 \%$, and $93.2 \%$, respectively.

No false-positive MDCTA interpretations and only one case of false-negative interpretation were found in comparison with the surgical findings of the 22 donors who underwent nephrectomy with an accuracy of $95.5 \%$. The results of this study did not correspond well with those of earlier studies, including those of Asghari et al., [5] who reported that MDCTA showed an accuracy of $96.7 \%$ and $100 \%$ for arteries and veins, respectively, and the Alam [8] study that reported $97 \%$ accuracy for arteries and $100 \%$ accuracy for veins.

The advantage of our study is that it is a prospective, multicentre study that avoids the selection bias of the retrospective studies. However, it also has some notable limitations. No surgical confirmation of cases with a complex vascular anatomy was performed and the accuracy rates were provided only for the less complicated kidneys. Also, the small size of the study population. Lastly, the radiation dose to the patients who received MDCTA was not estimated. 


\section{Conclusion:}

In conclusion, MDCTA correctly identified the necessary exclusions for renal donation and helped to determine the preferred kidney to be harvested based on the parenchymal and vascular findings. The accuracy of the detection of renal arterial and venous variants with MDCTA was $100 \%$ and $95.5 \%$, respectively. Information regarding the vascular anatomy and high-quality $3 \mathrm{D}$ display obtained with thin collimation provided a vascular map to help surgeons avoid complications.

\section{References}

1- NITIN P.G., SATYABRAT G. and VIJAYA R.: MDCT evaluation of potential living renal donor, prior to laparoscopic donor nephrectomy: What the transplant surgeon wants to know? Indian J. Radiol Imaging. Oct-Dec., 24 (4): 367-378. doi: 10.4103/0971-3026.143899, PMCID: PMC4247506, 2014.

2- LINDA C.C., SHEILA S., DORRY L.S., et al.: Role of MDCT Angiography in Selection and Presurgical Planning of Potential Renal Donors, American Journal of Roentgenology, 199 (5): 1035-1041, 2012.

3- HAZIROLAN T., ÖZ M., TÜRKBEY B., et al.: CT angiography of the renal arteries and veins: Normal anatomy and variants. Diagnostic and Interventional Radiology, 17 (1): p. 67, 2011

4- EL FETTOUH H.A., HERTS B.R., NIMEH T., et al.: Prospective comparison of 3-dimensional volume rendered computerized tomography and conventional renal arteriography for surgical planning in patients undergoing laparoscopic donor nephrectomy. The Journal of Urology, 170 (1): pp. 57-60, 2003.

5- ASGHARI B., BABAEI M., PAKROSHAN B., et al.: Role of multidetector computed tomography for evaluation of living kidney donors. Nephro-urology monthly, 5 (4): p. 870, 2013.

6- DING S., MEYSTRE N.R., CAMPEANU C., et al.: Contrast media extravasations in patients undergoing computerized tomography scanning: A systematic review and meta-analysis of risk factors and interventions. JBI Database System Rev. Implement Rep., 16 (1): 87-116. doi: 10. 1 1124/JBISRIR-2017-003348, 2018.

7- AGHAYEV A., GUPTA S., DABIRI B.E., et al.: Vascular imaging in renal donors. Cardiovasc. Diagn. Ther., doi: 10. 21037/cdt. 2018. 11.02, 2018.

8- ALAM A., CHANDER B.N. and JOSHI D.P.: 3-D spiral computerised tomographic angiography in evaluation of potential renal donors. Medical Journal Armed Forces India, 59 (3): pp. 205-208, 2003.

9- MONTÓN C.S., RODRIGUEZ C.M., EL KARZAZI E., et al.: CT imaging of presurgical evaluation of potential renal transplant donors: What do surgeons should know? European Congress of Radiology, 2014.

10-RANKIN S.C., JAN W. and KOFFMAN C.G.: Noninvasive imaging of living related kidney donors: Evaluation with CT angiography and gadolinium-enhanced MR angiography. American Journal of Roentgenology, 177 (2): 349355. 2001

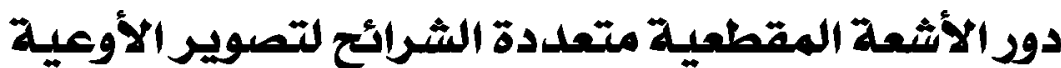

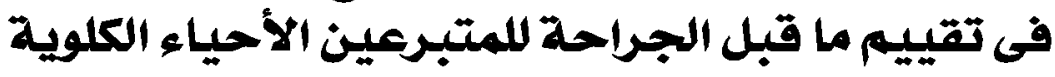

\author{
تعتبر عملية زرع الكلى من المتبرعين الأحياء أفضل علاج لمرضى الفشل الكلوى.

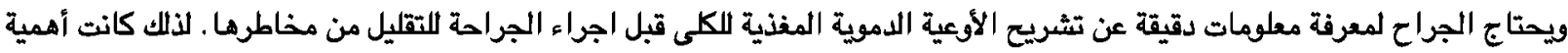 \\ الفحص باستخدام الأثعة المقطعية متعددة الشرائح لأنه يعطينا معلومات عن التشريح الطبيعى للأوعية الدموية ومتغيراته.

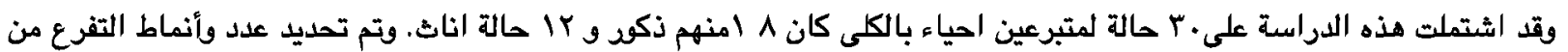

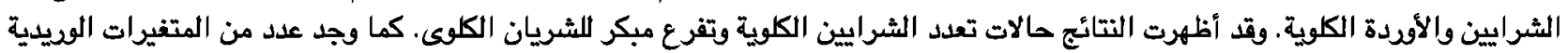

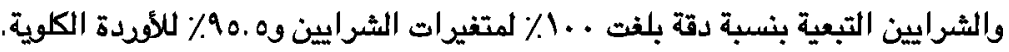 \\ ويعد فصص الأثـعة المقطعية متعدة الشرائح لتصوير الأوعية بشكل عام غير جائر ويسهل تتفيذه. ومتوفر على نطاق واسع. ويمكن الحصل \\ عليه بسرعة أكبر من فحوصات الأوعية الدموية الأخرى.
}

